\title{
SOME FEATURES OF TELEPHONE TRAFFIC AND THEIR EFFECT ON SERVICE.
}

BY J. G. WRAY.

Traffic, in the strict acceptance of the term, implies the transfer of goods or commodities from one person to another in exchange for other goods or commodities or for money. We, of course, may consider as traffic exchange of ideas over a telephone wire from one person to another and such a construction puts telephone calls within the meaning of the word.

Mr. S. ]. Larned in a recent paper before the Chicago Electrical Club enumerated several essentials of good telephone service.-

A vast clientele. It should be possible to reach all of one's friends or business correspondents by telephone. Uniform answering. There should be no long wait for the response of an operator. Rapid and accurate service. The party called for should be obtained quickly and there should be no interruption of the conversation. Communication should not be prevented by busy lines. (Busy calls arise from the fact that two persons desire to talk to a third party at the same time and such instances are common on very busy telephonelines.) Apparatus and other plant should be well maintained. The telephone and its wires should receive proper expert attention with a view of minimizing interference with the service, and when out of order should be repaired promptly. Courteous treatment of the subscriber by the telephone employess and vice versa.

Consider first the part the st:bsicriber plavs in telephone traffic and in making either for good or for bad service. I am perhaps open to criticism from the laymen when I say that the subscriber's part is an important one and often militates against good service. Who has not called for a number and after waiting for a few min 
utes hung up the receiver with imprecations against the telephone service? In the meantime the tulephone apparatus has perhaps performed its functions properly and the operator is in a fair way to get the called subscriber. When the latter answershe may not have answered promptly-and finds no one on the line, he, and not the calling subscriber is certainly the aggrieved party.

False calls are a frequent and annoying source of complaint against the service and are caused in many ways in addition to the one just named. The calling party may give the wrong number or the wrong office. The number or office may be misunderstood by the operator, or the calling subscriber may change his mind and decide not to make the call. In case the call is from a subscriber in one office to a subscriber in another office there is of course always a chance of a misunderstood number resulting in a call for the wrong party.

I recently noticed a curious fact in observing traffic from 10 party-line subscribers in a city not 1,000 miles from Chicago. I noted the extreme smoothness and accuracy of the service, the apparent absence of any hitches or complaints and was surprised when I learned that the operator's load was practically 30 per cent. higher than operators' loads in similar service in Chicago. I can explain this condition only by assuming that the operator had the intelligent and courteous coöperation of the subscribers and this was apparent from such observations as I was able to make during a two hours' visit in the office.

Calls should be ansivered promptly lest they become lost and the called subscriber lose perhaps a chance for an important business transaction. Prompt answering and short conversations will always tend to keep the line free for other inward calls and will minimize busy calls, which more than anything else are a source of bitter complaint.

Practically 20 per cent. of all calıs made are never completed because the line callea for is busy. About four calls out of every five are completed properly. This feature of telephone traffic is one of the most annoying to the subscriber, but unfortunately is almost beyond the control of the telephone oompany. Many busy calls result, of course, from the fact that certain lines are in ase a great deal of the time. The subscriber may come to a realization of the fact that as the business on his line increases the probabiity that he is excluding other business calls with a busy signal increases even more rapidly: However, inasmuch 
as there is always the possibility that two subscribers may desire to talk with a third subscriber at the same time there will always be calls stopped by the busy signal.

Other things being equal, the busy reports that may be expected from telephone lines will become more numerous and will increase with the number of conversations carried on over that line. In actual practice, however, other factors enter in. The New York City telephones, for example, are reported busy about as often as the Chicago telephones, practically 20 per cent. The number of conversations per line on New York telephone lines, however, is much less than on the Chicago lines. We would therefore ordinarily expect fewer busy reports from the New York lines. The other factors entering in this particular case are undoubtedly shorter conversations by Chicago telephone users and a disposition to rent additional telephone wires where circumstances seem to warrant it. Another factor which has even greater bearing is the fact that the New York City telephone calls are crowded into a shorter day and that hour for hour the lines are nearly as busy as in Chicago.

Leaving aside any further discussion of the part the subscriber may have in that which will militate for good service we have only to remark that if the subscriber would exercise the same courtesy and good judgment in his use of the telephone that he would show under ordinary circumstances in dealing with his business acquaintances face to face there would be a marked improvement in the service and the trials of the unjustly maligned telephone operator would be considerably mitigated.

Uniform answering with rapid and accurate service can only be accomplished by minimizing the work on each call and by giving an operator enough calls to keep her busy and not any more than she can handle properly. The service may be considered as being good when the average answering is in 6 or 7 seconds and when say 95 per cent. of all calls are answered within $3^{\prime}$ seccnds. This grade of service is obtained only under favorable conditions. The operator must not be overworked and she must be continuously under a competent supervising operator. The practice is to have a supervisor for every eight or ten operators. This supervisor should work under the direction of a chief operator.

One of the requisites of good service mentioned above is that the time and operations required of an operator on each individual call shall be a minimum. Obviously, the 
operator has no time for discussions with the subscribers on the merits of a complaint. These are turned over to the supervising operator for adjustment. It is the aim of the operating manager so to control the two factors just named that good service wiil result. By the proper manipulation of the intermediate distributing board he may, by increasing or decreasing the number of lines that an operator must answer, keep the operators load uniform under the fluctuations of traffic experienced in a telephone exchange. He must also minimize the work and time required of an operator on each particular call. This is done by paring down phrases that the operator must use, by providing machinery to eliminate certain manual operations, and easily read and interpreted signals to keep her informed as to the condition of the line called for, whether busy or out of order, or of the various phases of the connection; and charts to indicate changes of number of service, etc.

In a typical telephone exchange the load curve indicating the volume of traffic shows during the midnight hours a value of from $1 / 10$ of 1 per cent. to perhaps 5 per cent. of the maximum hourly load. This period of light load will vary from 7 to 14 hours, depending upon the location of the exchange and the habits of the telephone users. In the offices of the business district of a city, like Chicago, very few calls are made betwcen 7 P. M. and 7 A. M. Between the hours of $10 \mathrm{P}$. M. and $7 \mathrm{~A}$. M. the calls per hour will vary from $1 / 10$ of 1 per cent. to perhaps 1 per cent. of the maximum. Between the hours of 7 and 8 in the morning traffic will rise to perhaps 5 per cent. of the maximum. The rise will be extremely rapid, until the maximum load of the exchange is reached between 10 and 11 in the morning. About the noon hour there is a cessation of business and the tclephone traffic curve shows a drop of perhaps 40 per cent. below the maximum. After the lunch hour when business has been resumed the traffic curve rises to an afternoon maximum between 2 and 3 o'clock. This maximum will be less than the maximum in the morning and will in a typical office approximate 80 per cent. of the maximum traffic of the day. From 3 P.M .until 5 or 5.30 P.M. there will be a rapid decrease in the traffic load with an almost complete cessation of business at 6 P.M.

In a residence district the slump of traffic at noon-time is rot very well marked. There is, however, a decrease in the number of calls made late in the afternoon and a corresponding increase in the number of calls for the telephones of a residence district, 
the latter arising from the fact that the head of the house wishes to explain why he cannot come home for dinner, or to announce that he wishes to bring a fricnd. The evening traffic is also a feature of the residence district. Social calls are made, appointments for the theatre, invitations, etc. Evening traffic of a residence district often continues heavy until 9 or 10 o'clock, indeed, in one of the Chicago offices the evening traffic runs from 30 to 60 por cent. of the maximum and heavy traffic is maintained until nearly midnight. The curve of traffic indicates in a measure the habits of the people in the district.

In the Main office district in Chicago the business day may be said to have begun at 8.30 in the morning. There is a partial cessation of business for luncheon between 12.30 and 1.30 o'clock and the business day closes at about 5.30 P. M. For Central office also in the downtown district the business day is from 8.30 in the morning until 5.30 in the afternoon with scarcely any let up for lunch. Lawyers predominate in the Central district.

In Harrison office the day is the same as for Central and Main, but there is a marked reduction in the traffic between 12.30 and 1.30 o'clock.

The South office business day is practically from 8 o'clock in the morning until 9 o'clock in the evening, and even later, with no indications of a luncheon hour. North office telephone users are satisfied with a shorter day than the people of South office district, the limits being from 8 o'clock in the morning until 8 $o^{\prime}$ 'clock in the evening. For West office the limits are from 8.30 in the morning until 9 in the evening.

For Monroe office the traffic shows heavy business from 7.30 in the morning to 6 o'clock in the evening with a distinctly marked lunch hour between 12 and 1 . Monroe district is a manufacturing district.

Canal office traffic is largely like Monroe, extending from 8 in the morning unti1 5.30 P. M., with noon hour betwcen 12 and 1 .

Yards office telephone users like those of Monroe office begin in the day early and business is in full swing about 7.30 and continues until 5.30 with noon hour between 12 and 1 .

In Wentworth district, out in Englewood, the business of the day is done between $8 \mathrm{~A}$. M. and 6 P. M., with some indication that the people have lunch between 11.30 and 1 o'clock.

Hyde Park and Oakland offices, both in residence districts of similar character, show heavy traffic between $8 \mathrm{~A}$. M. and 8 P. M., with no trace of an hour for luncheon. 
Lake View office, also in a residence district, shows the work day beginning at $7.30 \mathrm{~A}$. м. and extending until 8.30 р. м. The habit of early rising was evidently formed before the advent of the Northwestern Elevated.

A similar comparison of traffic load curves of other cities will be of interest. In Philadelphia, for example, we find the heavy traffic between 9 A. M. and 5 P. M., with lunch between 12 and 1.30 .

In Boston the traffic shows a work day from 9 A. м. to 5 P. м., with time for luncheon in different offices varying from one and a half to two hours, between 12 and 2 o'clock.

New York telephone users seem to take life even more serenely than those of Philadelphia or Boston and we find the work day beginning as late as 9.30 in the morning and ending at about 4.30 in the afternoon, with two hours for lunch between and 12 and 2 o'clock.

Telephone traffic varies with the seasons as well as with the time of day.

The Canal office district of the Chicago Exchange shows a fluctuation of 50 per cent. between summer and winter traffic. This is caused by the vast lumber interests of the district, which practically close down during the winter months. There is a heavy rush of traffic in April and May, followed by a 40 per cent. reduction in traffic during July and August. In the fall business increases to a maximum in September. This is followed by a 50 per cent. reduction in traffic, culminating in January. A change in the character of the traffic from Canal district, however, has been noticed within recent years and the wide variations of traffic with the seasons are less marked. This is undoubtedly due to the change in the character of the district with the gradual building up of vacant prairie with residences, small shops, saloons, etc.

The traffic of all offices slumps decidedly during the summer months. There is a reduction of perhaps 30 per cent. durirg July and August, the vacation period.

The volume of traffic of a telephone exchange is also an unfailing index of general business conditions. This is shown by the fact that during 1894, 1895 and 1896 there was a very slight increase in traffic. With the return of prosperity, however, the traffic has increased by leaps and bounds until now it will approximate four times as heavy as during 1895 and 1896.

In passing it will be of interest to note that for 10 hours per day the traffic of Chicago Ex.changes ranges above the average hourly 
traffic figured on a 24 hour basis. For the other 14 hours per day the traffic is much lower than the average hourly traffic.

The average traffic for the maximum hour is about $2 \frac{1}{2}$ times the average traffic of the day', and perhaps 200 or 300 times the traffic of the hour of minimum traffic. The percentages and ratios of traffic given herein take no account of rushes of traffic for short intervals due possibly to the news of a prize fight, a fire, a panic or a foot ball game. These and the tremendous rushes of traffic always preceding or following every important holiday make a severe test of the resources of the operating plant.

The traffic of Saturday forenoon is always the heaviest of the week and is taken as a basis for the adjustment of operator's loads and the loads on trunk lines. The adjustment of the operator's load must be made with a view of handling the traffic well during the busiest hour of the day. Experience has shown that approximately one-eighth of the business of the entire 24 hours must be handled during the busiest hour.

From the above it can be readily seen that the capacity of the operators and the physical telephone plant must be extremely flexible to take care efficiently of the rapid and extremely wide fluctuation in loads just described.

To the advantage of the telephone manager be it said that the human machine is extremely well adapted to the handling of this fluctuating load. A well-trained operator will frequently take three or four calls in rapid succession and complete them almost simultaneously.

Just a word on the efficiency of the tclephone plant. Assuming an efficiency of 100 per cent., when all the subscribers' lines are in use all the time, we find that in actual practice they are working under an efficiency of only 2 or 3 per cent.

Assuming 100 per cent. efficiency when the apparatus used by an operator is in use all the time we find that in actual practice it is working under an efficiency of 25 per cent.

Thousands of dollars worth of multiple jacks lie in the switchboard practically idle. Some are perhaps never uesd.

The traffic of a telephone exchange determines the capacity and design of a telephone central station equipment and the size of its operating force. Changes in traffic whether a decrease due to business depression, a change of contracts to a message rate basis or to any other cause; or an increase caused by new telephone subscribers, by better business conditions or perhaps by a change of policy in the matter of party lines or Private Brauch 
Exchanges must be met promptly by a corresponding readjustment of facilities and operating force to enable the business to be carried on economically and well. 